\title{
Climate Change and Africa
}

\author{
Paul Collier*, Gordon Conway** and Tony Venables*** \\ $6^{\text {th }}$ May 2008.
}

\begin{abstract}
The impact of climate change on Africa is likely to be severe because of adverse direct effects, high agricultural dependence, and limited capacity to adapt. Direct effects vary widely across the continent, with some areas (eg eastern Africa) predicted to get wetter, but much of southern Africa getting drier and hotter. Crop yields will be adversely affected and the frequency of extreme weather events will increase. Adaptation to climate change is primarily a private sector response and should involve relocation of people, changes in the sectoral structure of production, and changes in crop patterns. The role of government is primarily to provide the information, incentives and economic environment to facilitate such changes. Adaptation will be impeded by Africa's fragmentation into small countries and ethnic groups, and by poor business environments. On the mitigation side, there is a need to design emissions trading frameworks that support greater African participation than at present, and that include land-use change. Mitigation undertaken elsewhere will have a major impact on Africa, both positive (eg new technologies) and negative (eg commodity price changes arising from biofuel policies).
\end{abstract}

Views expressed are those of the authors and do not represent institutional positions. Thanks to the OXREP editorial board and Aditi Maheshwari and Malcolm Smart for helpful comments.

* Director, Centre for the Study of African Economies, Oxford University

** Imperial College London and Chief Scientist, UK Department for International

Development.

*** Oxford University and Chief Economist, UK Department for International Development. 


\section{Introduction}

Climate change has implications for Africa which are highly distinctive. Its climate is likely to be affected more severely than that of other regions. This is compounded by the far greater exposure of its economy to climatic variation. In contrast to this atypically severe exposure to effects on production, Africa's role in emissions of carbon is atypically minor. Its past economic activity has not contributed to the accumulated global stock of carbon, its current activity accounts for only a trivial proportion of global emissions, and future projections suggest that it will continue to be marginal. Hence, whereas in other regions the key issues concern how to reduce carbon emissions, in Africa they concern the adaptation of production to changing, and mostly deteriorating, opportunities. Further, whereas for other regions the main adverse consequences of global warming occur only far in the future and are uncertain, in Africa many of the adverse consequences are already apparent.

At the root of climate change is global warming caused by anthropogenic emissions of carbon dioxide, methane and other greenhouse gases. The warming occurs worldwide and temperatures are rising on the African land mass and in the surrounding oceans. But Africa is distinctive in the combination of climate change effects. First there is evidence that Africa is warming faster than the global average and this is likely to continue. The recent data for Africa is given in figure 1,

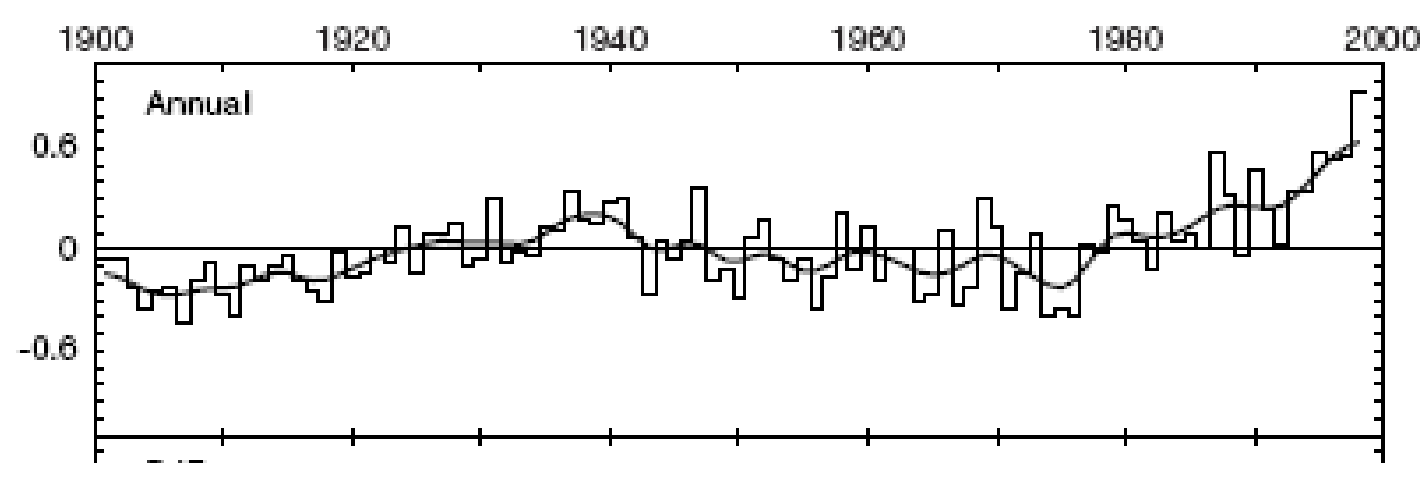

Figure 1: African annual mean temperature anomalies ${ }^{\circ} \mathrm{C}$ for the past 100 years. ${ }^{1}$

\footnotetext{
${ }^{1}$ Hulme, M., et al. (2001)
} 
Second, because Africa is such an enormous landmass, stretching from about $35^{\circ} \mathrm{N}$ to $35^{\circ} \mathrm{S}$, the climatic effects are very different according to location within the continent: there is no Africa-wide climate effect. Some areas of Africa will become drier, others wetter, and some regions may derive economic benefit, while most are adversely affected. And because mainland Africa is divided into fifty countries, these geographic variations imply not just that the impact effect is that some people gain while others lose, but that these redistributions are essentially between countries.

Third, agriculture is the largest single economic activity in Africa, accounting for around $60 \%$ of employment and, in some countries, more than $50 \%$ of GDP. Some of this activity is already close to the limits of plant tolerance, so changing climate will have an immediate and direct effect, beyond that in many other regions of the world. Charting out these likely impact effects is the subject of Section 2.

The economic consequences of these climate induced technological changes depend upon human responses. A complex set of changes, most adverse but some advantageous, create scope for reducing the adverse effects and even some net gains as long as the opportunities for adaptation are fully realized. However, over the past half-century, Africa's economies have not displayed a high degree of adaptability. Although households have considerable experience of coping with temporary shocks, such defensive flexibility has not been combined with sustained ability to adapt to new circumstances or adopt new technologies. At the macroeconomic level factor reallocation between sectors has been far more limited than other regions despite the prominence of 'structural adjustment'. One manifestation of this is Africa's continued dependence upon the same narrow range of commodity exports. At the microeconomic level, technical progress has been slower than other regions both among farms and manufacturing firms. An implication is that a key reason to fear that the consequences of rising carbon levels will in aggregate be highly adverse for Africa is that adaptation will be inadequate, with contingently adverse effects being realized and opportunities for gain missed. Thus, while attention is usually focused on the overall adverse exogenous effects of climate change on Africa - the region as a victim of circumstances beyond its influence - it might be more important to consider how capacity to adapt can be enhanced. This is the subject of Section 3. 
Globally, attention on climate change is predominantly focused not on adaptation but on carbon and methane emissions and mitigation. While there are some actions that Africans can take to reduce their emissions - particularly to do with land use and deforestation - by far the most important aspects of mitigation for Africa are the implications of the mitigation strategies chosen by the rest of the world. At one extreme, some strategies for global mitigation have serious adverse consequences for Africa and so would be damaging for the region even if they succeeded in arresting global warming. At the other extreme, some strategies create new income-earning opportunities for Africa although whether these opportunities are harnessed is again contingent upon human response. This is the subject of Section 4.

\section{Impact}

Attempting to understand the effects of climate change on Africa is fraught with difficulties. While some things are known and relatively well understood there is still great uncertainty about the key climatic processes. There is also much that is simply unknown.

The African climate is determined at the macro-level by three major global drivers (the Inter Tropical Convergence Zone, The El Niño - Southern Oscillation and the West African Monsoon), but how they interact and how they are affected by climate change is poorly understood. What we can be sure of is that global warming affects their outcomes, increasing the incidence and severity of the droughts, floods and other extreme weather events that they produce. In general, the drier subtropical regions will warm more than the moister tropics. Northern and southern Africa will become much hotter $\left(4^{\circ} \mathrm{C}\right.$ or more) and drier (precipitation falling by $10-20 \%$ or more) (Figure 2). In eastern Africa, including the Horn of Africa, and parts of central Africa average rainfall is likely to increase (by $15 \%$ or more). In general the best assumption is that many regions of Africa will suffer from droughts and floods with greater frequency and intensity. The risk of drought in Southern Africa is related to the occurrence of the El Niño phenomenon in the Pacific, and there has been a tendency for these to become more prolonged and frequent (Figure 3). 

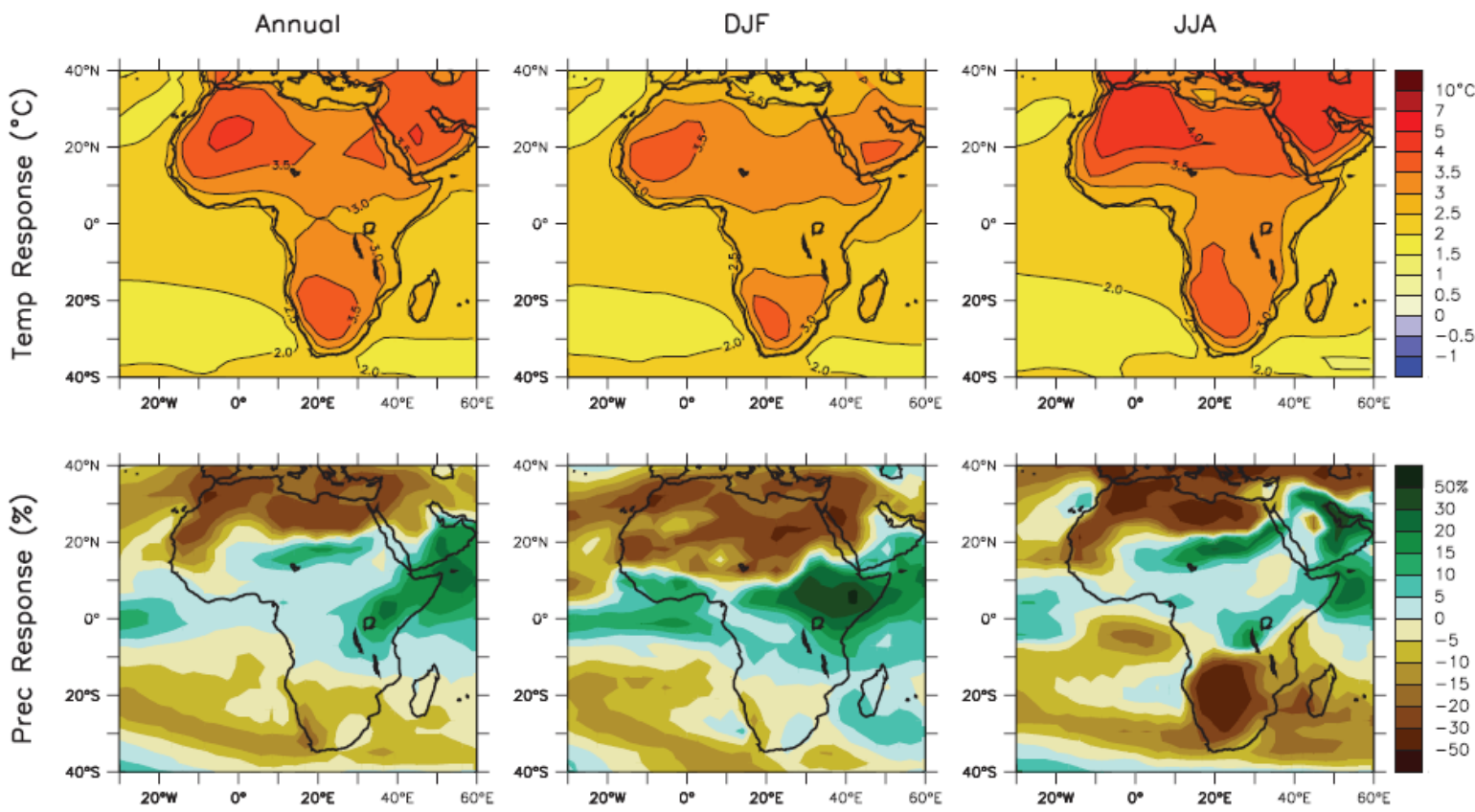

Figure 2: Temperature and rainfall projections for Africa; change from 1980 - 99 to 2080 - 99 for IPCC scenario A1B, averaged over twenty one Atmosphere-Ocean General Circulation Models. ${ }^{2}$ Annual average (left), December-February (centre), June-August (right).

Despite these strong likelihoods, there is much that we don't know. For example, the countries of the Sahel may get wetter or remain dry. The Sahel has experienced many multidecadal periods of drought since the last glaciation. ${ }^{3}$ We are in one such period now (Figure 4). Whether this current period is another natural episode or is the result of environmental degradation or of global warming we do not know. Probably it is a combination of these factors. Global warming is likely to exacerbate droughts such as these, increasing their frequency and intensity, but whether the current drought will continue is uncertain.

\footnotetext{
${ }^{2}$ Christensen et al (2007)

${ }^{3}$ Brooks(1998).
} 


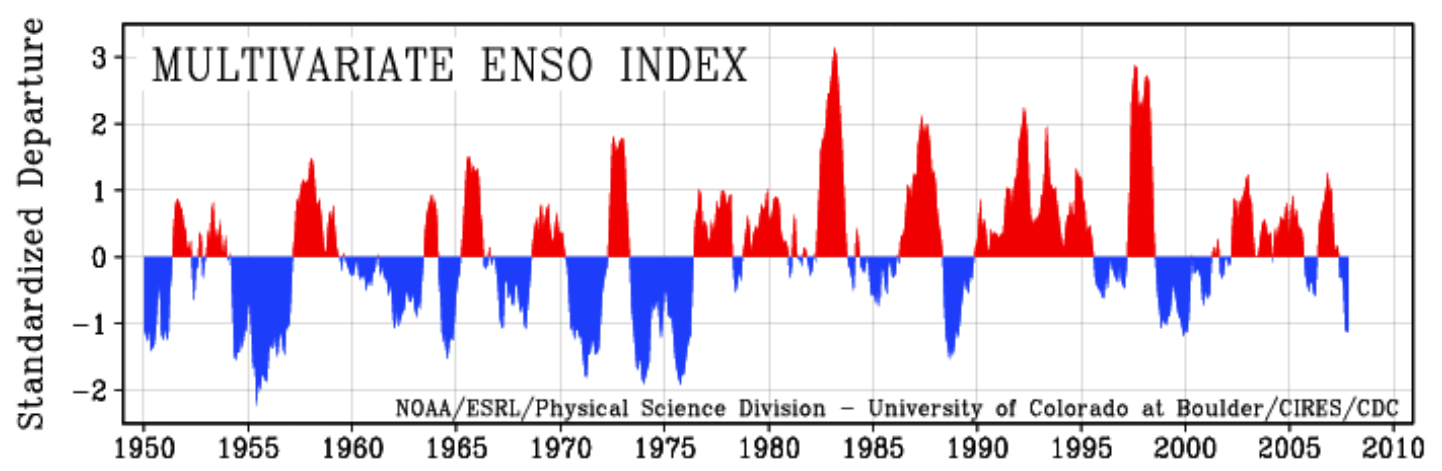

Figure 3: The alternation of La Niña (blue) and El Niño (red) events. (The Multivariate ENSO Index is based on six variables measured across the Pacific). ${ }^{4}$

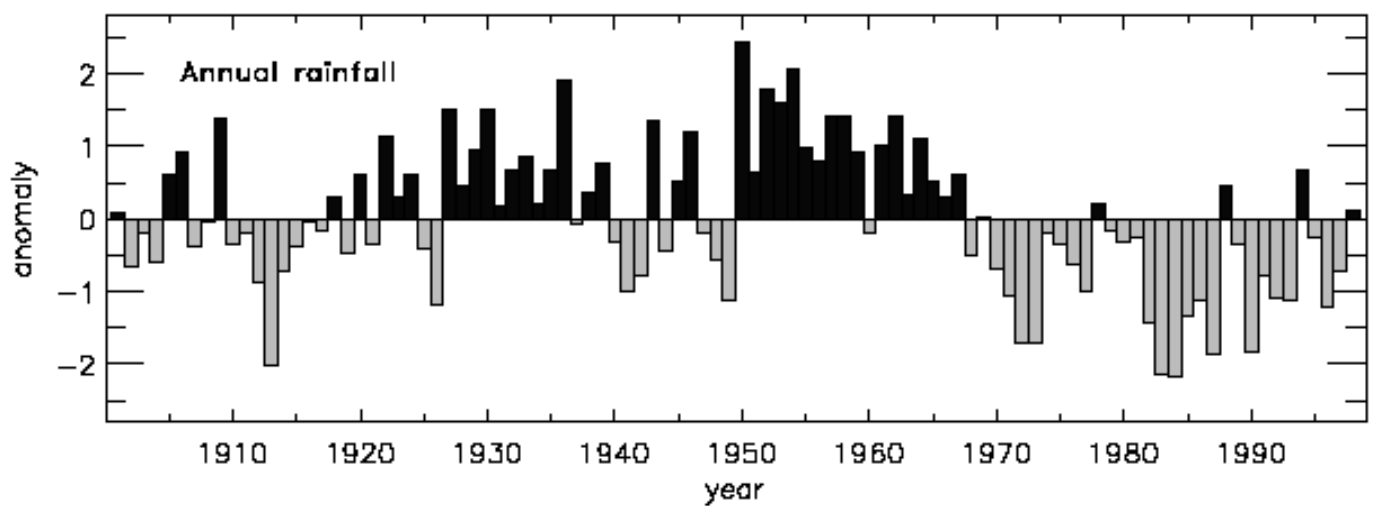

Figure 4: Annual rainfall anomalies representing the region $10^{\circ}-20^{\circ} \mathrm{N} ; 25^{\circ} \mathrm{W}-30^{\circ}$ E, roughly corresponding to the Sahelian zone. ${ }^{5}$

We are also unsure about the future flows of several of Africa's major river systems. Conflicting models of the flow of the Nile suggest it may be greater or less. In the Sahel and in southern Africa even a uniform decrease in rainfall will hit the river flows disproportionately hard. In wetter areas a $10 \%$ reduction in rainfall would have virtually no effect on the perennial drainage density, whereas in drier areas, for example in the basins of the Zambezi and the Limpopo, its effect would be far greater than $10 \%$ (Figure 5).

\footnotetext{
${ }^{4}$ http://www.cdc.noaa.gov/people/klaus.wolter/MEI/

${ }^{5}$ Brooks (2004).
} 

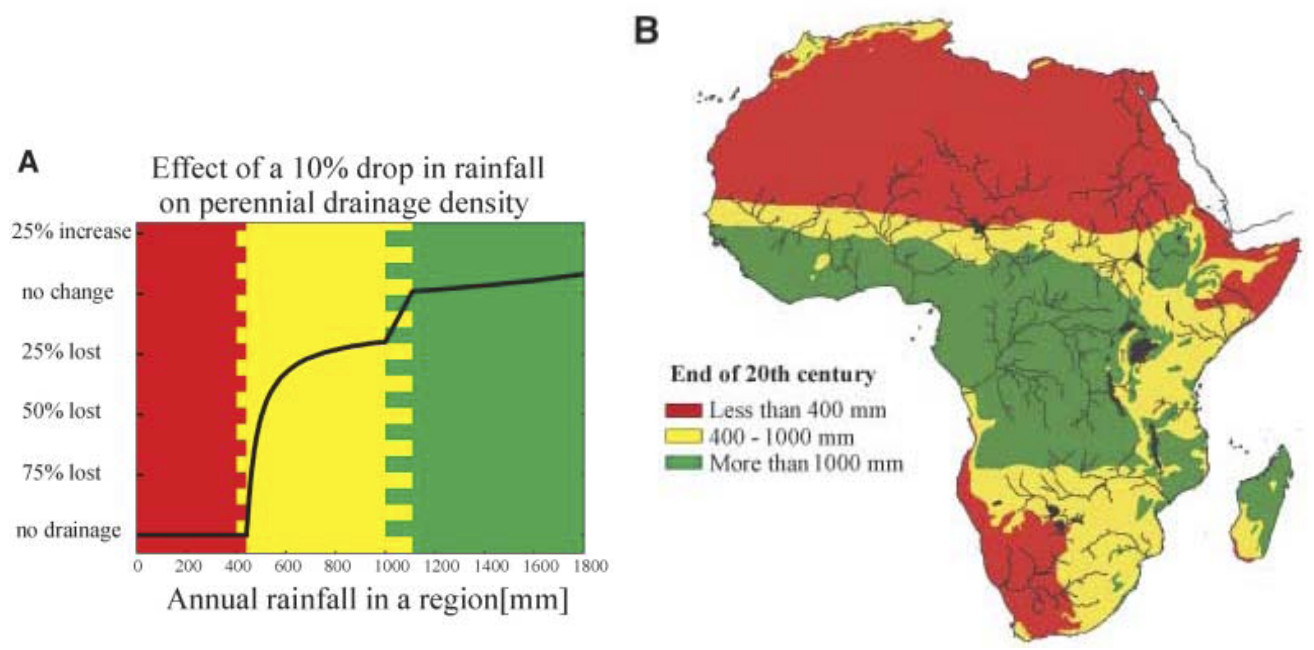

Figure 5: Rainfall and drainage regimes in Africa ${ }^{6}$. The intermediate regime (yellow) is unstable in the sense that a reduction in rainfall leads to a proportionately larger reduction in drainage and river flows.

How will these climatic changes affect African economies? By far the most important effects will be on agriculture, although these effects are also the least certain. The IPCC concludes that current conditions of chronic hunger are likely to be made worse. This is in large part because the proportion of arid and semi-arid lands is expected to increase (by 5-8\% by the 2080s) and partly because of depleted water resources. Impacts on agricultural output vary from country to country, with the IPCC projecting reductions in yield in some countries of as much as $50 \%$ by 2020 , with small-scale farmers most vulnerable. ${ }^{7}$

Higher temperatures will directly change crop yields. The area suitable for agriculture, the length of growing seasons and yield potential, particularly along the margins of semi-arid and arid areas, are expected to decrease. Many crops in Africa are grown close to their limits of thermal tolerance. We already know that just a few days of high temperature near flowering can seriously affect yields of crops such as wheat, fruit trees, groundnut and soybean. ${ }^{8}$ Such extreme weather is likely to become more frequent with global warming, creating high annual variability in crop

\footnotetext{
${ }^{6}$ De Wit et al (2006).

${ }^{7}$ Boko et al (2007)

${ }^{8}$ Challinor, et al (2006).
} 
production. But more prolonged high temperatures and periods of drought will force large regions of marginal agriculture out of production. The maize crop over most of southern Africa already experiences drought stress on an annual basis. This is likely to get worse with climate change and extend further southwards, perhaps making maize production in many parts of Zimbabwe and South Africa very difficult if not impossible. Wheat yields in North Africa are also likely to be threatened.

These adverse effects need to be combined with the potentially benign 'carbon fertilization effect' on plant growth caused by elevated levels of carbon dioxide. Greenhouse and field chamber experiments show that the carbon fertilization effect is capable of producing substantial increases in yields. But the latest analyses of more realistic field trials suggest the benefits of carbon dioxide may be significantly less than initially thought - an 8 to 15\% increase in yield for a doubling of carbon dioxide for responsive species such as wheat, rice and soybean, but not all crops are responsive, in particular maize and sorghum. Hence this offsetting factor may be less than has previously been assumed. ${ }^{9}$ The most significant effect may be in eastern and north east Africa where rainfall is likely to rise by $10-20 \%$, and the carbon fertilization could produce higher agricultural productivity. Estimates of yield losses elsewhere (including $\mathrm{CO}_{2}$ fertilization) are $18 \%$ for wheat in northern Africa and 22\% for maize in southern Africa. ${ }^{10}$ Proximity to the equator and low elevation amplify negative effects, and in worst affected countries (such as Senegal and Sudan) yield losses reach $50 \%{ }^{11}$

In general, the ideal conditions for a crop is evidently crop-specific, and since the existing choice of crops can be presumed to be appropriate for current conditions, changing conditions will tend to reduce yields in the absence of adaptation, but may open as many possibilities as they close once adaptation is considered. While a farmer who continues to grow maize will not benefit from the rising levels of carbon, farmers who switch from maize into a responsive crop and are able to reproduce experimental conditions would reap significant gains.

\footnotetext{
${ }^{9}$ Warren et al (2006)

${ }^{10}$ Warren et al op cit

${ }^{11}$ Cline (2008).
} 
While the effects on agriculture are likely to predominate, there are three other effects of significance. Higher temperatures, and higher peak temperatures, will also affect health. High peak temperatures (above $30^{\circ} \mathrm{C}$ ) will increase mortality, particularly in large conurbations, although the effect is modest in the overall context of African mortality. The effects via disease will probably be more substantial via the increase in disease-carrying insects. For example, the geographical distribution and the rates of development of mosquitoes are highly influenced by temperature, rainfall and humidity. We may expect an extension of the range of malaria carrying mosquitoes and malaria into higher elevations, particularly above $1000 \mathrm{~m}$. There have been resurgences of malaria in the highlands of East Africa in recent years. Many factors are probably involved - poor drug treatment implementation, drug resistance, land-use change, and various socio-demographic factors including poverty. But there is also a strong correlation with climate change. ${ }^{12}$ The temperature in the highlands of East Africa has risen by $0.5^{\circ} \mathrm{C}$ since 1980 - much faster than the global average - and this is correlated with a sharp increase in mosquito populations.

Both malaria and dengue are expected to spread substantially unless countered. Malaria already inflicts enormous costs on Africa over-and-above their direct effects on health. Gallup and Sachs (2001) argue that, controlling for other factors, the impact of intensive malaria is to reduce income by two-thirds; a 10\% reduction in malaria is associated with $0.3 \%$ pa higher growth. Hence the spread of malaria, and the concomitant increase in the difficulty of its control, may imply high though currently unquantifiable long term costs.

The rise in global temperatures will in turn lead to a rise in sea levels, by a metre or more by the end of the century. Such a rise would affect some 6 million people in the Nile Delta. Sub-Saharan Africa is likely to be less affected because it does not yet have large urban population concentrations in deltas. Again, however, the extreme sub-division of Africa into many small countries implies that even these modest effects are highly concentrated in a few countries: in Ghana the coastal zone occupies less than $7 \%$ of the land area but contains $25 \%$ of the population and so even

${ }^{12}$ Pascual et al. (2006) 
relatively small rises could have damaging effects on the economy; and the tiny state of Gambia is at risk of having its capital city entirely submerged.

Finally, greater exposure to flooding will have severe effects on infrastructure most notably the road system which is currently predominantly unpaved and therefore particularly vulnerable to erosion from flooding. Although it is not possible to quantify the cost of the increased proneness to climatic shocks, the typical such shock in a developing country reduces GDP in the year of the shock by around $0.4 \%$ (Collier and Goderis, 2008).

We now turn to how Africa can best adapt to these changing conditions.

\section{Adaptation}

While most of the effects described above are adverse, some are potentially favourable. The carbon fertilization effect is positive and East Africa appears likely to benefit from wetter climates. However, the most general implication is that the consequences will depend upon the capacity to adapt to change. Even the potentially favourable carbon fertilization effect will not benefit those farmers currently growing non-responsive crops unless they switch to responsive crops. The adverse effects, such as the increased incidence of drought, could have disastrous consequences unless appropriate defensive action is taken. In this Section we consider in turn the responses of three distinct classes of actor: the African private sector; the African public sector; and international actors, some regional and others global.

At an overarching level the key effects are changes in the relative productivities of different locations within the region, and an increase in production risk. Adaptation to these effects will predominantly be by private actors and can take three broad forms: people can move location, workers can change sector or, if they remain in the same sector, they can change technique - the way in which they engage in their economic activity. We first discuss these possibilities, and then discuss how they can be induced. 
Evidently, an appropriate response to changes in the relative productivities of location is the relocation of labour and capital towards the relatively favoured places. However, African conditions present several impediments. The movement of people is constrained both by the informal restrictions of strong ethnic identities and the formal restrictions of national boundaries. Africa is even more sub-divided into ethnic groups than it is into countries so that ethnic identities create barriers to movement even within a country. There is currently controversy over the extent to which population movements due to the drought in the Sahel have contributed to the conflict in Darfur, as pastoralists seeking water resources clash with sedentary arable farmers. Cross-border migration on a mass scale can be stymied by political restrictions and even where it is permitted has the potential for violent conflict. For example, the movement of population from arid and landlocked Burkina Faso to coastal Cote d'Ivoire at its peak was so large that around $40 \%$ of Ivoirian residents were Burkinabe. This facilitated a populist politics that was instrumental in triggering a political collapse into civil war.

Even where people are able to migrate across ethnic or national boundaries, they may not be able to gain access to land. In most of Africa land rights still reflect some ancestral claim and are not readily marketable.

The reduced productivity of many locations is largely specific to agriculture, the sector which accounts for more than $60 \%$ of the African labour force: in major parts of Africa farmers are going to be faced by technological regress. Further, the adverse effect of climate change on agriculture is much more pronounced in Africa than in other regions. The climatic variation will more severe in Africa, and African agriculture is still overwhelmingly rain-fed and so more vulnerable. This has two important implications, one macroeconomic, the other concerning comparative advantage and the inter-sectoral allocation of resources.

The macroeconomic issue is that African economies will become more prone to shocks. Collier and Goderis (2008a) analyze which structural policies in factor markets are most appropriate to reduce the macroeconomic consequences of natural disasters. They find that disasters have less severe macroeconomic consequences if employment legislation permits greater flexibility, enabling easier hiring and firing of 
workers. A related significant structural policy is the ease with which firms can be established and closed: greater flexibility reduces the cost of natural calamities. The payoff to flexibility is substantial. Hence, labour market liberalization and a lighter regulatory burden on firms look to be appropriate responses to the threat of climate change, although such considerations have been entirely omitted from the nowvoluminous economic literature on climate change.

The inter-sectoral issue is that climate change will shift Africa's comparative advantage away from agriculture. The efficient response would therefore be to shift resources out of agriculture into other activities that are less vulnerable to climate. Potentially, this socially optimal reallocation of resources will occur simply through normal market processes. However, to date the pace of inter-sectoral resource reallocation has been modest. African economies remain predominantly agricultural because other sectors have not generated many opportunities. Much of the growth in the services sector has been due either to public sector employment, which is fiscally constrained, or is in informal activities such as petty vending, which are perhaps more a symptom of limited alternative opportunities than a sign of dynamism. The industrial sector has generally been in relative decline, reflecting the retreat from the costly cul-de-sac of protectionism. In an earlier phase governments attempted to force industrialization through trade restrictions but domestic markets were far too small for this to be viable. Hence, on the basis of past evidence, technical regress in agriculture is likely to be reflected predominantly in a decline in agricultural incomes rather than in a reallocation of factors to other sectors. This suggests that a policy priority in responding to climate change should be to raise the factor absorption capacity of the non-agricultural sectors.

There is considerable scope for such increased absorption. Export oriented manufacturing offers a way to achieve this sectoral shift, but Africa has to face the obstacle of the dominance of Asian countries in these markets. To date, many African governments have severely handicapped both industrial and service sectors. One indicator of this poor policy environment is the annual Doing Business survey of the World Bank, which provides a wide range of precisely comparable performance measures. Most African countries are far down the international rankings on these measures, implying that all tradable activities other than those which depend upon 
locationally-specific advantages are liable to be uncompetitive. Examples of impediments to business are unreliable electricity, long delays at ports, and expensive telecommunications. Other developing regions used to have similar problems, but governments have been more vigorous in addressing them. Even in Bangladesh, where overall governance is very poor, the government has done enough to enable the garments sector to flourish in export markets, resulting in more than two million jobs. Similarly, in India, well-functioning international telecommunications and attention to quality in education have enabled the e-services sector to create millions of exportorientated jobs. Matching these sector-specific policy achievements of Bangladesh and India are surely feasible goals for most African governments. They may well be the most important response to climate change.

Were such a strategy of sectoral reallocation from agriculture to succeed, an implication is that the rate of urbanization would increase. Africa is currently the least urbanized region and would be urbanizing even without climate change so accelerated urbanization would take it along a well-trodden development path, although possibly at rates of expansion that are exceptionally high. In China such a relocation of population has occurred rapidly and on a massive scale, driven not by climate change but by other reasons for changing relative economic opportunities. Much of this migration has been towards coastal areas, an option impeded in Africa by the extreme sub-division of the continent and the large number of landlocked countries.

While faster inter-sectoral resource allocation is desirable, it is clear that a substantial proportion of the African labour force will remain in agriculture for decades to come. These households will need to adapt their agricultural techniques. Substitutions between crops and crop varieties can reduce income losses and even lead to overall gains. Evidently, substitution should be towards those crops and crop varieties that are most responsive to increased carbon dioxide and those best suited to changed local climatic conditions.

In addition to the trend change in relative yields, there will also be increased year-onyear variability. Adaptation to the increase in production risk could potentially be either through holding relatively liquid assets or through insurance. The liquidity option is problematic. Often financial assets carry negative real interest rates, and real 
liquid assets either have high costs of storage, such as grain, or are themselves vulnerable to climatic shocks: notably, during a drought the price of livestock will decline due to synchronized pressures to sell (Dercon, 2002).

In the absence of transactions costs insurance would always be the first-best response to risk, but it is well understood that agricultural insurance is problematic. Other than through neighbours it is costly to observe effort levels and so there is a severe risk of moral hazard. Currently, overwhelmingly the most important form of crop insurance in Africa occurs informally, within small communities which can readily observe behaviour. Unfortunately, such neighbourhood insurance is inappropriate for climatic shocks since they are covariant across the community. It may be possible to develop insurance instruments which work in the conditions of rural Africa, such as insurance policies under which specified variation in a local rainfall index will trigger payments. A number of pilots are underway, varying in whether payment is made to government for disaster relief, to individual farmers, or to banks to allow the write-off of farmers' debts. However, designing such insurance contracts requires both that there is a long historical record of climate data, and that this record is expected to be a good guide to future probabilities. The former condition is absent in much of Africa, and the latter is threatened by climate change itself.

Hence, the best available responses to risk may be costly changes in production, notably switching production towards crops that are drought resistant such as cassava, and spreading production over a wider range of crops - diversification. However, as with all insurance strategies, the greater safety inevitably comes at the loss of average income. A further agricultural adaptation strategy is investment in irrigation. As rainfall becomes lower and more peaked, the return to storing it increases. Farm-level investments in irrigation are not well-suited to functioning as collateral because the benefits are highly location-specific, and so credit-constrained households may underinvest.

These adaptations depend upon the decisions of individual firms and households. Will they happen naturally as people learn about rising carbon levels or should public action attempt to induce them? One reason for believing that much of the adaptation will happen without government inducements is that the impact occurs only very 
gradually. Private decision takers are not caught by surprise by some sudden event of which the government has foreknowledge. Private actors are naturally forwardlooking and so gradual change need not imply any especial difficulty. However, private actors can be presumed to respond appropriately to changing conditions only if they have adequate information, appropriate incentives, and an economic environment conducive to investing in the required changes. Hence, the most promising strategy for government is to ensure that these three conditions are met.

One key role of the public sector is thus to provide the information and incentives that private actors need in order to induce adaptation. The most information-intensive aspects of adaptation are likely to be changes between crops and crop varieties. It is well-understood that the generation of information is an important market failure in smallholder agriculture: the incentives to free-ride are too strong. This is why governments around the world provide agricultural extension services. The need for adaptation increases the pay-off to public agricultural extension services. It also shifts the focus of the related agricultural research from yield-enhancement of existing crops. However, just as individual African farmers face an acute free-rider problem in the financing of research, so do individual African governments: agricultural research in Africa is a regional public good.

In addition to providing information, government needs to ensure that the private sector has the incentive to adapt. In many cases this requires that government (and donors) commit not to act. While the public sector should be pro-active in responding to the need for information, it should be cautious in directly trying to mitigate increased risks. In particular, interventions by government or aid donors that soften the consequences of adverse shocks have the inadvertent consequence of weakening the incentive to reduce exposure to them.

In respect of one key public good, the road network, climate change constitutes technical regress. Increased climatic variation, and in particular intense bouts of rainfall, can dramatically erode unpaved surfaces. The appropriate response here is to an extent ambiguous. Overall, the return on investment in roads is lower and so the appropriate size of the road network is smaller than would otherwise be the case. However, because the cost of maintaining a road network of any given size increases, 
the appropriate level of expenditure on roads may well rise. This is just one example of how the provision of public infrastructure will have to be adapted to climate change. As it becomes clearer what form climate change will take in particular countries, so action will have to be taken to 'climate-proof' infrastructure investments.

Are there areas where more direct government intervention in support of adaptation is valuable? The balance here is between market failures that impede the private sector's ability to adjust and public sector failure. For example, the difficulty faced by credit-constrained farmers in investing in irrigation opens a further role for public provision. In general, the record of African government investment in large-scale irrigation suggests that there are major difficulties with this approach, although there may be more scope for financing smaller-scale, local-level cooperation. Potentially, the government could require change by means of effective regulation. However, the history of agricultural regulation in Africa suggests that usually the regulatory route would meet such strong resistance as to have only limited effect. Most African governments lack the administrative capacity to enforce complex agricultural changes that are against the private interests of farmers.

We now turn to international cooperation to assist adaptation, starting with cooperation between governments within the region. As we have argued, the shocks to the region as a whole are considerably smaller than those to individual countries. This suggests that there might potentially be benefits from regional integration, and these could be derived through several different channels. The first is that regional integration might facilitate migration. However, we have already pointed to some of the difficulties here. Even where free movement of labour is part of long term regional integration plans, as in the East African Community, very little progress has been made to date. The second channel is trade. Countries may become more dependent on food trade both because of changing patterns of comparative advantage and because of the need to integrate markets to pool risk. Given the radically higher costs of land transport over sea transport, coastal Africa may be more cheaply integrated into global food markets than into the markets of landlocked neighbours. Further, regional trade in food is proving to be so vulnerable to political intervention that it is unreliable. For example, in response to the rise in global food prices the 
government of Tanzania has imposed restrictions on food exports to Kenya, despite both belonging to the East African Community. The third potential benefit of regional integration derives from improved cooperation on non-market inter-country linkages, in particular water. While increased rainfall in East Africa may increase flow in the Nile, drier and hotter conditions in Southern Africa may reduce the flow of the Zambezi significantly. There is potential for inefficient and inequitable water use - and ultimately conflict - unless regional cooperation is established.

International actions to assist African adaptation have both an ethical and a practical rationale. The ethical rationale is evidently that the rising levels of carbon dioxide are not attributable to Africa but to economic activity elsewhere, and so there is a strong case that the costs of African adaptation to these adverse externalities should be born by others. In practical terms, some of the public goods required for adaptation are regional in nature, such as climate information, agricultural research and transport infrastructure. Africa's extreme political sub-division means that it faces intense problems in supplying regional public goods, and international assistance can usefully substitute for these missing public goods. Assistance for adaptation also needs to be seen more broadly in the context of development policy. Climate change is likely to make development more difficult and diversification out of agriculture more necessary. This suggests that OECD trade preferences for African non-agricultural exports might become more important (Collier and Venables, 2007). Aid flows might need to be reallocated between sectors to support such diversification, and reallocated geographically to target those societies most severely affected. Finally, the most elementary step would be for the international community to do no harm. The bizarre prohibition by the European Union of genetically modified crops has slowed African use of genetic modification lest it precludes exports to Europe. Yet genetic modification is a useful means of speeding African agricultural adaptation.

\section{Mitigation}

Historically and to the present day Africa has made little contribution to the stock of greenhouse gases in the atmosphere. Data for per capita emissions of CO2 excluding land use change - indicate that in most African countries emissions are less 
than 0.5 tonnes per capita, one-twentieth that of the UK (Figure 6). Sub-Saharan Africa, with $11 \%$ of the world's population, accounts for just $3.6 \%$ of world emissions of CO2e, reflecting low levels of income and of energy consumption.

Nevertheless, mitigation is an important topic for Africa, for two reasons. The first is that the mitigation response of the rest of the world will impact on Africa. Future international frameworks for mitigation, in particular for emissions trading, create opportunities for Africa. And even without this channel, energy related innovation and changes in the prices of fuels and other goods will change the economic and technological opportunities open to Africa. The second reason is that there is one area where Africa is fast becoming a major greenhouse gas emitter. This is from land use change, in particular deforestation (Figure 7) for which Africa now accounts for $20 \%$ of world emissions (with world emissions from land-use change amounting to around $20 \%$ of total anthropogenic emissions). Much of this comes from land use change in the Congo basin, in particular the Democratic Republic of the Congo. A framework is needed that balances lower carbon emissions with productive use of forest areas, and which can operate in politically difficult environments.

We look first at the design of international mitigation frameworks and their treatment of deforestation, turning then to the impact on Africa of mitigation in the rest of the world. 


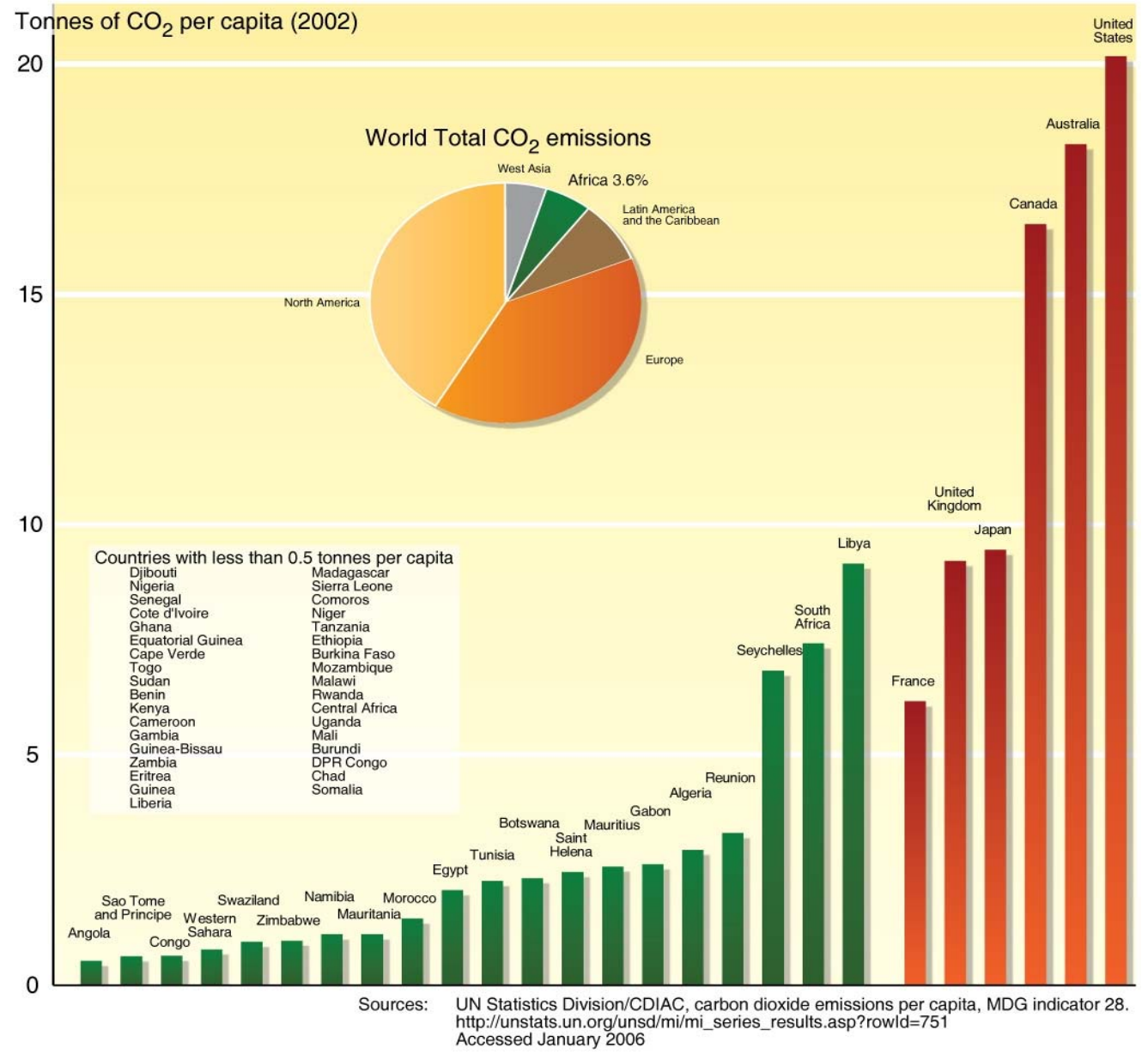

Figure 6: CO2 emissions per capita, 2002 (tonnes)

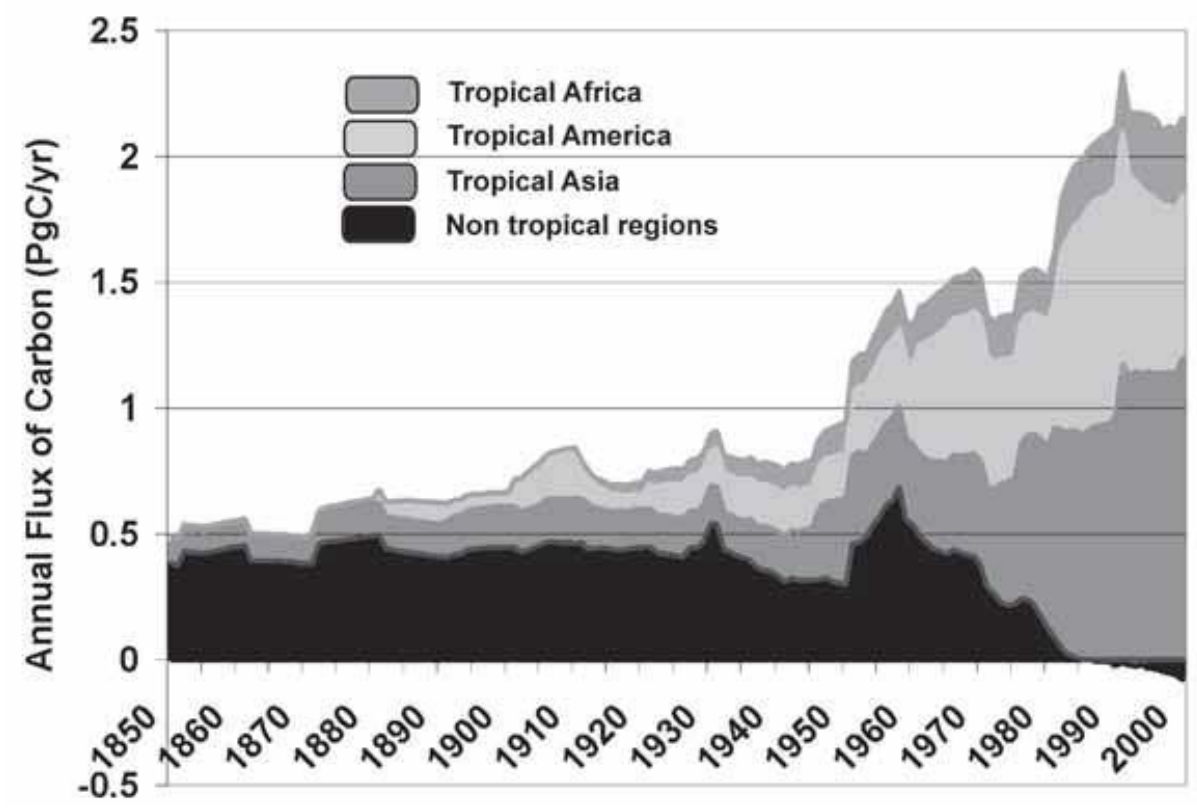

Figure7: Annual emissions of carbon from changes in land use. Vertical axis is gigatonnes carbon ( $\mathrm{Pg}=10^{15}$ grams). One gigatonne of carbon is $3.67 \mathrm{GT}$ of $\mathrm{CO} 2 .^{13}$ 
Under an idealised cap and trade emissions trading scheme each citizen would be endowed with a right to emit a specified quantity of CO2e (or each country endowed with the corresponding national total) and would be able to sell rights in excess of own emissions. Were emissions monitorable at the level of the individual citizen or country, such a scheme would provide incentives for reductions in CO2e. Depending upon the allocation of emissions rights it might also create a distinct channel for resource flows to low emission countries. In the hypothetical extreme in which each person was endowed with the same emission rights, the financial flows to Africa resulting from sales of carbon rights might be of comparable size to its current aid receipts of around $\$ 40 \mathrm{bn}$ pa. ${ }^{14}$ In effect, the allocation of carbon rights to Africa would become its aid programme. The abrupt creation of such valuable rights without reference to existing patterns of usage is, of course, entirely implausible. Somewhat more realistically, 'contraction and convergence' schemes propose national emissions quotas that would start from current levels and very slowly converge - over several decades -- to being proportional to population. Since, over this time frame international economic convergence would substantially reduce disparities in usage, the redistributive aspect of carbon trading would be correspondingly reduced.

While a new channel for massive transfers to Africa may appear attractive both to African governments and to aid advocates, it is likely to prove illusory. A realistic political economy of public international financial transfers would suggest that transfers through emissions trading might largely substitute for existing financial transfers rather than supplement them, since both provide budgetary resources. Such a switch might be welcomed by African governments: in particular it would release them from conditionality. In effect, were Africa to export carbon rights the revenue consequences would be analogous to the export of oil. Unfortunately, to date Africa's oil revenues have been less well used than its aid receipts so this substitution need not be beneficial (Collier, 2006). Further, while the allocation of aid within the continent is purposive and so broadly related to need and governance, revenues from carbon rights would be unrelated: Angola would receive approximately as much per capita as Uganda.

\footnotetext{
${ }^{14}$ If two tonnes of CO2e per head were sold at $\$ 30$ per tonne.
} 
In between entitlements based on existing usage and equal entitlements per capita, is an equal entitlement per unit of GDP. This would create an incentive to reduce the carbon-intensity of GDP without discouraging the growth of GDP itself. For example, it would penalize a carbon-profligate economy such as America, and reward a carbonefficient economy such as France. Unfortunately, on this metric Africa looks like America. Its low carbon emissions are entirely due to its poverty: its structure of income generation is highly carbon-intensive.

While the above arrangements are hypothetical, the Clean Development Mechanism (CDM) already functions as an institution by which developing countries can earn income from reducing CO2e emissions. Unfortunately, Africa barely participates in this scheme. Of the \$2-\$3bn pa currently being traded through the CDM just 2\% of payments go to Africa. Even this grossly overstates the participation of low-income Africa. As of January 2008 there were 21 CDM projects in Africa (out of around 1000 worldwide), all except two of which were in either North African countries or South Africa (the exceptions being a gas recovery project in Nigeria and the West Nile Electrification project in Uganda).

There are several reasons for the virtual absence of the CDM in low-income countries across Africa. One is limited African capacity to prepare or implement credible CDM proposals. Such proposals require detailed and complex project documents, construction of baselines, and arrangement of the financial packages necessary for CDM participation. CDM projects often have elements of foreign direct investment and attracting such investments requires that the investment climate as a whole is attractive, a factor lacking in many African countries. As a market mechanism the CDM has attracted large volume/ low cost sources of emissions, and most African countries do not have the volume to justify the high transactions costs. Another reason is that, within the CDM, the approved methodologies for project selection are heavily biased towards energy and industrial and synthetic gas sectors, all areas in which Africa has relatively little presence. On the energy side, Africa has potential for hydro, for reducing energy losses in transmission and distribution, and for unconventional schemes for using natural sources of methane as a power source. Yet none of these are easily handled by existing CDM methodologies. Deforestation 
remains outside the CDM, and aforestation/ reforestation projects are not accepted by the EU-ETS - the world's largest carbon market.

To move forward, several lines of action are needed. The first is to develop African capacity to participate in the CDM as presently constituted. There is a role here both for knowledge dissemination and for skills development. Aid has a role in providing technical assistance for project preparation and also in levering finance for environmental projects.

The second is to broaden the CDM to include a wider range of potential African projects - in the power sector, waste disposal and above all in avoided deforestation. At present aforestation and reforestation schemes are eligible for the CDM, but forest management and conservation projects are excluded. The difficulty of handling avoided deforestation illustrates clearly the fundamental design problems of the CDM. A CDM project requires a ‘baseline scenario’ or counterfactual against which payments can be made. For a forest project this is the rate at which the particular area of forest would be cut down in the absence of the CDM intervention. There is no reasonable way to establish such a baseline; and if there were, it would create perverse incentives as people sought to signal that - in the absence of CDM project status - they would have been likely to cut down the forest. The project level basis of the CDM also creates acute problems of 'leakage'; preserving one area of forest is of no value if another area is cut down instead. These arguments point to the need to switch from a project based to a programmatic approach. Such an approach would operate at a much wider level than separate projects, perhaps at the national or regional level. The baseline could be constructed on the basis of estimates of historical emissions, and payments made for emissions reduction below these baseline levels.

Steps in this direction are being taken by the Forest Carbon Partnership Facility, based at the World Bank, which has two elements. The first is to assist countries in building up estimates of the baseline levels of their current forest stocks and forest emissions. The second is to pilot national schemes for reducing forest emissions below baseline levels. Under such schemes countries would receive payment if actual forest emissions were below the baseline. Of course, many problems remain; even if a 
government is participating in such a scheme and has set targets for reduced forest emissions, there are still problems both of monitoring outcomes and of enforcing measures to reduce deforestation. Any scheme which depends upon government preventing people from taking up profitable opportunities may require a degree of effective and honest governance beyond the capacity of many African governments.

While carbon trading arrangements will create incentives for mitigation within Africa, Africa will also be affected by the mitigation efforts of the rest of the world. There are two main channels. One is a diversion effect, arising as developed countries switch their patterns of expenditure in pursuit of lower carbon consumption. The other is a creation effect, as technological change raises the efficiency of new green technologies.

The diversion effect is already evident. One manifestation is consumer concern with 'food-miles' and the potential damage that this could do to African suppliers of nontraditional agricultural exports. Another more important one is changes in relative prices, including the current high prices of cereals and many other food crops. While the main factors driving the higher prices are increased food consumption (particularly in Asia with associated use of cereals as animal feed) and drought in some food producing regions, the conversion of food producing land to biofuel production is a further element. $10 \%$ of world maize production now goes to biofuel production, and the startling fact is that, with current technology, the opportunity cost of filling the tank of an SUV with gasoline is enough food to feed a person for a year. Since Africa is a net food importer, these price changes are having a significant negative effect on the terms of trade of many African countries. The fundamental problem here is not with biofuel production per se, but with the fact that production subsidies in some OECD countries are causing inappropriate biofuel crops to be grown in the wrong places. In the US biofuel production displaces maize otherwise destined for food supply. In contrast, the opportunity cost of Brazilian biofuel production from sugar-cane is much lower, while in Mozambique just $9 \%$ of arable land is presently cultivated, and much of the rest is suitable for biofuel production from sugar-cane or jatropha with little or no impact on food production. 
On the technology side, world mitigation efforts will lead to a shift in the pattern of R\&D towards the development of low carbon energy sources. This is a slow moving process that will affect a very wide range of technologies. New biofuels will use more advanced technologies (cellulosic or algae based) with much less impact on food production. There are prospects for much improved plant varieties, possibly genetically engineered, able to cope with drought and other environmental changes. In some areas there may be a prospect of technological 'win-wins' for Africa. The analogy is sometimes made between new green technologies doing for electricity supply what mobile telephones did for communications in Africa. Instead of having to invest in landlines - or large scale power distribution networks - decentralised power supply based on small scale hydro or solar power might be able to bring power to new areas in a manner that his both greener and cheaper. Whether such 'win-win' technologies will emerge remains unclear, although two general points can be made. One is that Africa may have a latecomer advantage, and be able to leapfrog technologies that are in use in the developed world, going straight to more efficient technologies in a number of areas. The other is that, while new technologies will be developed in high income countries, adapting them to be suitable for Africa is likely to involve some costs, and will remain bedevilled by the small size of African markets.

\section{Conclusions}

Climate change is not a problem of Africa's making, yet parts of Africa stand to be particularly hard hit because of their geography, their agricultural dependence, and because of difficulties that adaptation will face, as outlined in this paper. These observations point to a range of actions that need to be pursued by African governments and by the international community.

In the long term world mitigation that is effective in stabilising atmospheric levels of CO2 will be valuable to Africa, as it will for the rest of the world. For the next halfcentury the key development issues are African adaptation to future climatic deterioration and opportunities for African participation in schemes for mitigation. World mitigation efforts will also affect Africa indirectly via price effects and technical change. Here, as in other contexts, production subsidies to OECD farmers 
can damage developing country interests. Shaping new technologies so they are applicable in Africa, and developing regions more widely, may require public financial support.

The impact of climate change is already being felt in Africa and strategies for facilitating adaptation need to be developed. The private sector has been adapting to technical progress for centuries, but will now have to adapt to technical regress in some areas. The role of government is primarily to supply information, to maintain incentives, and to increase the flexibility of the economic system both to secular change and to short run shocks. There is also a public role for support for agricultural research, and there will be growing demands on public expenditure as it becomes necessary to design infrastructure to cope with a harsher climate.

In addition to their mitigation responsibilities, developed countries and the donor community must recognise that climate change will make poverty reduction objectives more difficult and more expensive. There will be direct financial burdens (eg from infrastructure needs) and a particular role for donors in providing the regional public goods which Africa lacks. 


\section{References:}

Boko, M., I. et al, 2007: Africa. In Parry, M.L. et al, eds Climate Change 2007: Impacts, Adaptation and Vulnerability. Contribution of Working Group II to the Fourth Assessment Report of the Intergovernmental Panel on Climate Change, Cambridge University Press, Cambridge

Brooks, N. 1998 . Climate and History in West Africa, in G. Connah (Ed.), Transformations in Africa: Essays on Africa's Later Past, pp 139-159. Leicester University Press, London and Washington.

Brooks, N. 2004. Drought in the African Sahel: long term perspectives and future prospects. Tyndall Centre for Climate Change Research. http://www.tyndall.ac.uk/publications/working_papers/wp61.pdf.

Challinor, A.J. et al 2006. Assessing the vulnerability of crop productivity to climate change thresholds using an integrated crop-climate model, In: Schellnhuber, J., et al (ed), Avoiding Dangerous Climate Change, Cambridge University Press pp.187-194.

Christensen, J.H. et al, 2007 Regional Climate Projections, in Solomon, S.D. et al, eds. Climate Change 2007 : The Physical Science Basis. Contribution of Working Group I to the Fourth Assessment Report of the Intergovernmental Panel on Climate Change, Cambridge University Press, Cambridge

Cline, W.R. (2008) ‘ Global warming and agriculture’ Finance and Development, 45, 1.

Collier, P., 2006, Is Aid Oil? World Development, 34, 9, 1482-97.

Collier, P. and B. Goderis, 2007, Commodity Prices, Growth and the Natural Resource Curse: Reconciling a Conundrum, CSAE WPS 2007/15 , 2008, Does Aid Mitigate External Shocks?Review of Development Economics, forthcoming 2008a, Structural Policies for Shock-Prone Commodity Exporters, mimeo, Centre for the Study of African Economies.

Dercon, S., 2002, 'Income Risk, Coping Strategies and Safety Nets', World Bank Research Observer, 17, 141-66.

De Wit, M. et al 2006 Change in surface water supply across Africa with predicted climate change, Science 311, 1917

Gallup, J.L and J.D. Sachs 2001 The economic burden of malaria, Am. J. Trop. Med. Hyg., 64(1_suppl), 2001, pp. 85-96 
Houghton, R.G. 2005 Tropical deforestation as a source of greenhouse gas emissions. In Moutinho, P. and S. Schwartzman (eds.) Deforestation and Climate Change. Amazon Institute for Environmental Research, pp13-21

Hulme, M., et al. 2001 'African climate change: 1900-2100’. Climate Research 17, $145-168$

IFPRI 2007 'The world food situation; new driving forces and required actions', processed December 2007.

IPCC 2007 Climate Change 2007. The 4th Assessment Report of the IPCC. Working Group I The Physical Science Basis Ch. 11 Regional Climate Projections. Intergovernmental Panel on Climate Change.

Pascual, M. et al. 2006, Malaria resurgences in the East Africa Highlands: Temperature trends revisited, Proceedings of the National Academy of Sciences, 103, 5829-5834

Rainforest Foundation 2007 'Clouds on the horizon; the Congo basin's forests and climate change'.

UNEP/GRID-Arendal. Carbon Dioxide (CO2) emissions for selected African countries in 1997. UNEP/GRID-Arendal Maps and Graphics Library. 2002. Available at : http://maps.grida.no/go/graphic/carbon_dioxide_co2_emissions_for_selected_ african_countries_in_1997.

Warren, R. et al 2006 Understanding the regional impacts of climate change. Research Report Prepared for the Stern Review on the Economics of Climate Change. Tyndall Centre for Climate Change research, Working Paper 90 